\title{
MARTA TRABA O EL SALTO AL VACIO
}

\author{
POR \\ ELENA PONIATOWSKA \\ Montclair State College
}

En la casa de Bell, en Nueva York, se inclinaba hacia adelante para darse mejor, sus dos codos sobre las rodillas, su fleco en los ojos, su rostro ofrecido venía al encuentro del interlocutor, un rostro ávido, ardiente. Eso mismo hacía en sus conferencias, en Smith, en Stanford, en MIT, en Brandeis, en Maryland, en el New York State University. Hablaba de pie. «No puedo comunicarme sentada», y desde el pequeño círculo de luz que la rodeaba surgía un fenómeno conmovedor: el de la entrega y el desgaste. Hubiera podido caer muerta allí mismo, pero no iba a dejar sin respuesta a los estudiantes; daría todas las explicaciones, contestaría pregunta tras pregunta, los familiarizaría con Bacon, De Kooning, Dubuffet, Szyslo, Obregón, Botero, Cuevas; barrería la pavorosa extensión del continente latinoamericano para internar a sus oyentes en Colombia, país que siempre amó y donde contribuyó más que nadie a la aceptación del Arte Contemporáneo y a la creación del Museo de Arte Moderno. Con su voz apresurada y generosa les arrojaría ideas, los iría envolviendo hasta sacudirlos; sí, América Latina tenía mucho que dar; la prueba, esta mujer pequeña frente a ellos; esta mujer vehemente que sabía ofrecer una cultura desconocida. Súbitamente los ponía en contacto con sociedades que no están industrializadas y proponen valores culturales distintos.

Mucho antes de que García Márquez traspasara las fronteras, Marta Traba hizo oír su voz. Sus tiempos son los de Carpentier -entonces sólo traducido al francés-, los de Lowry que contempla durante horas el Popocatepetl, Lowry aplastado bajo el volcán, Lowry frente a una naturaleza gigantesca y muda, el Tepozteco que se levanta en la llanura amarilla o verde según la estación y los pueblos tirados como confetti a la mitad de los valles. Se calcinan al sol, cubiertos por el polvo, absolutamente 
huérfanos: "Cruz, cruz, cruz, que se vaya el diablo y venga el niño Jesús.» Piedras calientes y gente que se va convirtiendo en piedra, pueblos encerrados en sí mismos y condenados a la memoria que de ellos se tenga como lo dice Elena Garro en Los recuerdos del porvenir. Marta Traba se sentó sobre la piedra para luego abrirla, picarla, quitó la maleza, desempolvó memorias, amplió el círculo, abrió cabezas, arremetió contra el slogan «no hay más ruta que la nuestra»; necesitó un cincel y un mazo enormes, y con piedritas fue señalando otros caminos. La escucharon espantados. ¿Con qué autoridad se atrevía a hablar esta joven mujer que sacudía virulentamente su fleco negro? «América Latina es ahora una negación y una ambición. En nuestra batalla para ser autocríticos nos enfrentamos a los que custodian los viejos mitos y estamos determinados a demolerlos sin piedad. No más mentiras.» Se vuelve una agitadora cultural en una época en que la cultura es un círculo cerrado. No sólo divulga un tema desconocido en América Latina como el arte moderno, sino que promueve y elogia a aquellos que han sido calificados de locos. Es vanguardista y por lo mismo revolucionaria. Cuevas no sería el concepto Cuevas que manejamos sin Marta Traba, que se atreve a llamar ridículos a los muralistas y anecdótico e inmediato al muralismo. Sus apariciones en la televisión son fulminantes. Tiene mucho de enfant terrible, sabe seducir y declara abiertamente su vocación de domadora. Más tarde habrá de confirmarlo a Igor Molina: «Personalmente me fascina que me digan domadora. Trato de ejercer ese papel con el mayor encanto posible. Pienso que los hombres que he domado (maridos, hijos, compañeros de trabajo y demás esclavos) estaban tan contentos como yo de la situación.»

Pero también quiere ser Juana de Arco. Sus juicios son temidos por lapidarios y sobre todo por inesperados. No ha habido hasta ahora una crítica de arte tan fresca y desenvuelta. Antes, Margarita Nelken diseccionó las obras con un método casi científico. Marta Traba califica y se lanza al ruedo. Habla en voz muy alta, se hace notar, y en el restaurante, desde las otras mesas, los parroquianos se vuelven a verla con la certeza de que se trata de una actriz. iY qué bella!

Pero me estoy precipitando un poco a la manera de Marta Traba, que en un momento quiere acabar con el cuadro. Aunque después tenga que regresarse. Así escribió: «Pienso retrabajarlo», decía siempre. Ahora mismo, su última novela, En cualquier lugar, terminada en Washington en el año 1982, esperaba ser trabajada. Su hijo Gustavo la hizo llegar a la Editorial Siglo XXI, acompañada de la siguiente carta:

«Marta dejó una novela inédita, En cualquier lugar. A principios de febrero estará allá en México, en Siglo XXI. Yo la leí con mucha emoción, pero no soy crítico ni sé de literatura. Sé que Marta pensaba re- 
escribirla, pero a mí me parece una pena dejarla inédita. Pienso que es buena.»

A lo largo de los años, Marta conservó el mismo fleco, el mismo pelo negro y tupido a lo Juana de Arco en torno a su cara redonda. Más tarde lo describiría en la novela En cualquier lugar. "Se cepillaba cuarenta veces, veinte de cada lado, el pelo negro lacio que iba acortando a medida que pasaban los años, pero que todavía aguantaba cayendo a un lado de la cara y le permitía echarlo hacia atrás con un movimiento aún desafiante. Bajaba la escalera del edificio con paso rápido, y sólo en el borde de la acera, con la mano lista para llamar un taxi, le sobrevenía un velocísimo dolor; ¿dónde estaba?, ¿en qué ciudad? ¿Adónde iba?»

La última vez que la vi fue en Nueva York. Habíamos pasado la mañana en casa de Bell Chevigny. Al despedirnos, dijo que prefería caminar. Atravesaría Central Park. Le haría bien el aire frío. Desde el taxi la vi cruzar Columbus Avenue, enfundada en su chaqueta de piel, presurosa dentro de sus medias color vino. (Nosotros decimos «vino»; los franceses dicen Bordeaux.) Busqué su rostro, pero el cuello del chaquetón y sobre todo su cabello espeso me lo impidieron. Por la ventanilla la miré caminar, pequeñita bajo los rascacielos. Sola. Es la última imagen que conservo de ella.

Cuando Rose Minc repartió una circular amarilla con los temas a tratar en este simposium, las mujeres y el proceso creativo, el impacto de la historia y los cambios políticos y sociales, las nuevas realidades de la crítica literaria tal y como la ven las escritoras, pensé que en todos ellos encajaba Marta Traba. Ejerció la crítica no sólo en el campo de la pintura, sino en el de la literatura. Si hablaba de Jackson Pollock, también lo hacía de Sherwood Anderson, el escritor que la hizo reconocer y adorar la provincia norteamericana. Dos Passos o Fitzgerald siempre estuvieron presentes en la descripción de la ciudad, y cuando examinaba un cuadro alusivo los recordaba. Amó tantas calles porque antes las leyó y se le trenzaron para siempre los empedrados morados de Nueva York con las plazas vacías de Boyacá o una escalinata en Siena.

Marta Traba se la vivió superponiendo exilios, pero me pregunto, ¿no somos todas las latinoamericanas unas exiliadas? Isabel Allende es chilena y vive en Venezuela; Silvia Molloy, Elvira Orphée, en Estados Unidos; Luisa Valenzuela, argentina, primero en México y luego en Nueva York; Julieta Campos nació en Cuba; Rosario Ferré, puertorriqueña, va y viene a caballo sobre dos países; mi apellido no es precisamente chichimeca; Elena Garro se refugió en París, y Clarice Lispector, ucrania, fue a dar a Brasil y acabó quemándose la mitad de la cara con un cigarro olvidado en la cama; Rosario Castellanos murió sola en Israel, electrocutada por 
una lámpara doméstica. ¿No somos, a veces, como me lo escribió Rosario Ferré en una carta, un jironcito de hilo?

Nacida en Argentina, graduada en letras en la Universidad Nacional de Buenos Aires, con una especialización en arte con el historiador Jorge Romero Brest, el primero que sistematizó el panorama del arte latinoamericano (a quien toda la vida reconocerá como su maestro), Marta Traba decide irse a vivir sola a Europa. Quiere ingresar a la Escuela de Altos Esudios en la Sorbona y a la Escuela del Louvre. Sus abuelos llegaron de Galicia a Buenos Aires tan pobres, que ni siquiera tenían maletas, y entraron al país con una gallina bajo el brazo y un atado en la otra mano. La obsesión de la gallina aparecerá en muchos textos de Marta. En En cualquier lugar, su novela póstuma, escribe en las últimas páginas: «... Luis se acordó que Alí le había contado que su abuela, que era una campesina turca, siempre viajaba con gallinas, por si acaso, aunque nunca supo precisar cuál era la eventualidad que ella temía. Bueno, también la manta, por si acaso.» La madre de Marta tocaba el paino en las salas de cine mudo y llevaba a la niña todos los sábados a cines de barrio para ver al Gordo y el Flaco, Laurel y Hardy. «De modo — dice Marta- que cuando por primera vez vi una película de verdad, Intermezzo, de Ingrid Bergman, me asaltó una sensación de pudor y maravilla; creí que en el cine sólo había pastelazos a la cabeza; no sabía que la gente podía exponer sus sentimientos, contar su intimidad, y para mí fue ésa una revelación extraordinaria.»

Agobiada porque llegaban mil extranjeros diarios en el primer gobierno de Perón, la estudiante Marta decidió dejar Argentina. «Me cansé de andar en bus», le contó a Igor Molina. "Cada vez que el bus se detenía, un racimo de personas se entremataba y, a patada limpia, intentaba entrar. Lo mismo para salir de él. La marabunta te obligaba a permanecer hasta el final de la ruta, de modo que jamás llegabas a tu destino. Entonces se me creó una especie de horror y decidí irme. En parte, la causa fue el desorden, y en parte, la locura desatada de Perón, que gritaba: 'alpargatas sí, libros no', con lo cual me tocaba envolver mis libros en papel de periódico no fueran a descubrir en la calle que yo era estudiante. Compré un pasaje de ida, dispuesta a no regresar jamás.»

Marta vivió en París el verano más caluroso de su historia. St. Germain-des-Près agonizaba al sol; las piscinas del Sena, los bateaux-lavoir, las peniches estaban atestadas de rubias de pelo largo convertidas en lagartijas y de hombres semidesnudos o francamente desnudos. ¿A quién de nosotros le ha tocado este París tropical? Sólo a Marta, que se asolea en la alberca de agua dulce, con su bikini verde, y se ufana: «... pero ya está el bikini y, por cierto, que la miran, lo cual en París no deja de ser 
una proeza». Muy pronto, entre sus idas a la Sorbonne y su École del Louvre, las galerías de arte de la Rue Bonaparte y la plaza Fürstenberg, el París de Vuillard y de Utrillo, el de Colette, Marta entra al laberinto del amor: «Pasen, pasen, vayan entrando.» Todos pasamos bajo este arco de brazos, todos doblamos el espinazo al mandato del refrán: «Por aquí se ha de pasar, tras, tras, tras, tras.» Se casa con Alberto Zalamea, el hijo del escritor, y tiene dos hijos, Gustavo y Fernando, sus inseparables compañeros de viaje. Con Alberto vive a orillas del lago de Castelgandolfo. El es corresponsal de prensa, ella una joven madre. «Es una etapa feliz, una cadena sucesiva de pequeñas felicidades que me llenan mucho. Vivimos de la caza y la pesca a orillas del lago.»

Una noche, el presidente Eduardo Santos, de paso por Italia, le propone a Alberto regresar a Colombia a trabajar en el diario El Tiempo. Consulta a Marta, ambos aceptan. Entonces se inicia una de las etapas más definitorias de la vida de Marta. En Colombia entra en contacto con una realidad desconocida: la de la pobreza y la de un continente en el que todo está por hacerse. Y Marta HACE. Ingresa a la televisión, organiza mesas redondas, foros, conferencias, se vuelve profesora de Historia del Arte en la Universidad de América, Universidad de los Andes y Universidad Nacional de Bogotá. Fundadora y directora del Museo de Arte Moderno, promueve a pintores jóvenes, se lanza a exposiciones nunca antes imaginadas, quiere sacar el arte del círculo cerrado de la élite; que los burgueses descuelguen sus marinas, sus manolas y sus crepúsculos para colgar una serigrafía de Myrna Baez, un dibujo de Amelia Peláez. Cada vez se vuelve una figura más polémica y más imprescindible en un país en el que mandan los militares. Sus comentarios cáusticos son repetidos en todos los círculos; temen su mordacidad, sus palabras, que son saetas. "Luego de la ocupación de la Universidad Nacional de Bogotá, un militar me preguntó (ya que era la directora de Cultura) dónde debían ponerse ciertas estatuas adquiridas por la Universidad. Le respondí que si no se había fijado en los destrozos que el ejército había hecho. Era absurdo preocuparse de la colocación de esculturas en una Universidad arrasada. Me mandaron llamar de la Comandancia, cosa que empavoreció a mis amigos, y ante el general reafirmé: "Debería usted pasar a la Universidad para ver cómo la ha maltratado el ejército'.» A raíz de esta conversación le dan a Marta un plazo no mayor de veinticuatro horas para salir del territorio colombiano con sus dos hijos, Gustavo y Fernando, deportada a Argentina.

«Para mí - dice Marta - fue como un mazazo en la cabeza, un golpe tremendo; me sentí coma María Antonieta en la guillotina, pero dado que el gobierno colombiano no paga jamás, no pudieron conseguir fiados sino 
dos pasajes de avión... y éramos tres. Entonces resolvieron alargar el plazo a cuarenta y ocho horas, casualidad que me salvó. Inmediatamente estalló en Colombia el más grande movimiento de opinión organizado por mis amigos; durante esas cuarenta y ocho horas clave llegaron al despacho del presidente Lleras centenares de cables rechazando la expulsión. Este movimiento, insólitamente, duró quince días, al final de los cuales el presidente habló por televisión y dijo cosas graciosas, como: "... a pesar de que era una destructora de las instituciones establecidas, a pesar. de que la señora Traba era la cabeza de punta de la Revolución cubana en Colombia, a pesar de que ella misma afirmaba de que Cuba era el único territorio libre de América, se había enterado que tenía dos hijos colombianos, por lo que decidía, de acuerdo a las consideraciones humanas, permitirle vivir en Colombia siempre y cuando no volviera a decir ni pío.'»

En 1966, Marta Traba, conocida por todos como crítica de arte y por algunos como autora de un bello libro de poemas, Historia natural de la alegría, se revela como novelista. En La Habana, un jurado compuesto por Alejo Carpentier, Manuel Rojas, Juan García Ponce y Mario Benedetti confiere a Las ceremonias del verano el premio "Casa de las Américas». Fogosa y entusiasmada, Marta se adhiere a la joven revolución y se transforma en «la compañera Marta». Estimulada por el premio, entrega a la prensa colombiana una estupenda Homérica Latina compleja, rica, seductora, sostenida no por la anécdota, sino por la atmósfera general, la propia narración que suplanta las tensiones dramáticas. Sus personajes son aquéllos que se contentan con poco y no tienen con que vestirse ni alimentarse. Asimismo logra la proeza de publicar siete libros en tres meses en diversos países: Puerto Rico - país que conoce a fondo-, México, Colombia y Venezuela: Historia abierta del arte colombiano, Dos décadas vulnerables en las artes plásticas latinoamericanas, La rebelión de los santos (sobre los santos de palo populares, que demuestran la voluntad de autonomía de la cultura puertorriqueña), Cuatro artistas puertorriqueños (Rodón, Rosado del Valle, Homar y Hernández Cruz), En el umbral del Arte Moderno, un ensayo sobre Velázquez, Zurbarán, Goya y Picasso; Mirar en Caracas, acerca del arte actual en Caracas, y Hombre americano a todo color, en que propone un modelo de imagen para tipificar al hombre americano a través de la obra de 16 artistas latinoamericanos.

No sé en qué momento Marta Traba empezó a sentir que vivir la vida era una terrible proeza. Quizá a raíz de la situación de Argentina. Quizá algo le cambió por dentro o no fue un cambio, sino que súbitamente afloró a la superficie una Marta de sangre y pulpa que no había estallado. 
Porque sus dos últimas novelas, Conversación al Sur y En cualquier lugar, son estallidos que ya se presentían en Homérica Latina, pero que ahora se abren como las flores rojas de la pasión. Marta empieza a dar otra pelea, ya no contra la retórica plástica, sino otra que parece no tener fondo, contra la miseria de los que sobreviven en América Latina. Ahora sus amigos son también los que habitan casuchas en la estación, montan un techo sobre un pequeño espacio libre entre dos estructuras, compran una puerta, una ventana y sobre una tabla sostenida por dos caballetes ponen la lámpara de Kerosen. De allí a la papelería del partido, los volantes, las corretizas, no hay más que un paso. Sus amigos son el Chajá, el Muerto, los flacos - y como todos son flacos--: uno es el Flaco Ortiz, otro el Flaco Pereda, otro el Caballo López. A todos los acecha la muerte. Su militancia política, su clandestinidad, el carnet, la lividez, la detención en la escalerilla del avión, la muerte. De pronto es la gente insignificante la que empieza a contar para Marta, la que se desquicia brutalmente. «Podría haber intentado fraternizar con los políticos locales superando ese bloqueo mental que le impedía entender nada cuando le hablaban, o decir siquiera una palabra en ese idioma que nunca había sido previsto en sus colegios ni en su universidad", pero prefiere a los otros, a los muchachos pálidos que no saben leer, sólo firmar. Marta empieza a desgarrarse y es entonces cuando escribe Conversación al Sur, publicada en 1981; dos mujeres hablan en un departamento de la desaparición y la tortura, del exilio y del luto; hacen el recuento de sus pérdidas, sabiendo también que, al final, la policía vendrá por ellas.

En el curso del relato magistral, Marta Traba le dice a la más joven: «No, yo siento que he caminado independiente. Que me he ido comprometiendo por mi cuenta y riesgo y no porque aprobara lo que estaban haciendo ustedes, no, la mayoría de las acciones me resultaban bastante disparatadas y siempre ineficaces, sino porque empezó a jugarse una cosa nueva; me refiero a la compasión, a la solidaridad con el otro. ¿Se perdió toda la lástima por el otro? Porque si se perdió es como si una sociedad entera se hubiera vuelto inhumana, ¿no te parece?»

Su libro Conversación al Sur lo convertí en sudario, lo llevé en mi bolsa durante muchos meses, lo amé intensamente. Nunca he leído nada mejor, más duro, más conmovedor que lo que Marta escribió acerca de las madres llamadas las «Locas de la Plaza de Mayo». Esa sí que es literatura y es denuncia. $\mathrm{Y}$ así también Marta conjuga a una gran escritora con un espléndido ser humano.

«... Sin decir nada, sin gritar, las mujeres levantaban las fotos lo más alto posible. ¿Para qué, si nadie las veía? Calculé que no pasaría mucho 
tiempo antes de que esas caritas casi infantiles fueran irreconocibles a fuerza de estrujarlas y sobarlas. Cerca mío, una vieja levantaba con las dos manos una foto de esas de estudio artístico de barrio. La muchacha de la foto sonreía tiesa, ladeando la cabeza como seguramente le había exigido el fotógrafo. Estaba sentada con las piernas cruzadas, medio ocultas por un traje de tul. Otra llevaba una foto carnet en la palma de la mano, protegiéndola como si fuera un huevo que acabara de empollar ahí mismo; fue levantándolo con delicadeza y empezó a moverlo de derecha a izquierda; mientras lo hacía, temblaba y las lágrimas le corrían por la cara, pero mantenía los labios apretados. Justo al lado, una sacó de la cartera una fotito enmarcada en un óvalo. Me miró y se sonrió como excusándose. No tenía más que fotos sacadas cuando era chico, ¿quién iba a pensar? Le pregunté, ¿qué edad tenía ahora? 'Cumple veinte años el mes que viene. Un chico de oro. Pensábamos hacerle una fiesta.' Casi no pudo terminar la frase, pero se repuso, suspiró y levantó también su marquito. Lo más alto que pudo. Empecé a sentirme mal sin hacer nada ni tener nada que mostrar. Levanté la lista con ambas manos y me quedé esperando. ¿Eso sería todo? ¿Llorar en silencio con otro que llora en silencio?

»Y fue cuando comenzó esa cosa que no puedo explicarte, Dolores. ¿Qué te diría? Que de repente alguien comenzó a gritar y los gritos se multiplicaron y en minutos la plaza era un solo alarido? Eso no te dice a ti nada, ¿verdad? ¡Hay tantas griterías por todos lados! Y a lo mejor te sonríes si te digo que yo, que no tenía nada que ver con nada, también me puse a gritar, no te sé decir de qué, como tampoco entendía ni una palabra de lo que las otras gritaban, porque las palabras estaban como tajeadas por sollozos y aullidos. Me pareció oír de vez en cuando: ¿đónde están?, ¿dónde están?', pero a lo mejor me lo imaginé. Sin embargo, debían preguntar algo que movilizaba la cólera general, porque la masa de mujeres se movió hacia adelante, como una marea. Avanzaban, nos entrechocábamos, tropezábamos unas con otras. La confusión era inenarrable mientras se echaban al aire centenares de hojas de papel. Yo hacía lo mismo que las locas, y no te puedo decir lo que sentía; como si me estuvieran por arrancar las entrañas y me las agarraran con una fuerza demencial para salvarlas. Pero ¿qué digo? No sé si fue así. Trato, ¿ves?, no puedo. Oí un amenazador rumor sobre mi cabeza y la bajé instintivamente; al momento comprendí que lo hacían las palomas, planeando despavoridas sin encontrar lugar donde posarse. Se mantenían en agónicos vuelos circulares, llenos de refriegas de plumas y picotazos frenéticos. Tropecé de frente con una muchacha que gemía; no tendría más de veinte años. ¿A quién habría perdido? ¿A su bebé, a su compañero, a sus pa- 
dres? No podía ver la foto estrujada entre ambas manos. Creí ver en un grupo un pedazo de la chaqueta de Elena y me abrí paso a codazos para encontrarla. Estaba a la mitad de un círculo que coreaba al unísono, y ahí sí pude entender claramente 'dónde están', 'dónde están'. Me daba la espalda, pero aunque le toqué el hombro y la sacudí, no se dio vuelta. Entonces le gritó su nombre. Ah, Dolores, si vos decís que la conociste bien, jamás la hubieras reconocido en ese momento. Para mí, que pasé la mitad de mi vida junto a ella, era una completa extraña. No quiero ni acordarme de esa cara desfigurada, la boca abierta gritando y sobre todo la piel, esa piel delicada que aparecía manchada, amoratada. No levantaba la foto de su hija, sino que la apretaba con las dos manos contra el pecho, encorvándose; una vieja acosada por la muerte. Le pasé la mano por los hombros y grité con ella. Hasta que todo se fue aplacando. Las locas comenzaron a separarse. Tres mujeres de edad indefinida calmaban a otra que levantaba el puño contra la Casa Rosada. Se empezaron a reacomodar las chaquetas, a retocarse las blusas, a poner la cartera en su sitio, se tocaban el pelo, miraban hacia todos lados buscando el lugar adecuado para salir de la plaza. El gentío raleó, y se vio el piso de baldosas tapizado de hojas mimeografiadas. Yo estaba anonadada, no podía reponerme tan rápidamente. De nuevo perdí de vista a Elena. Pasaron pocos minutos antes de que la plaza fuera quedando vacía. Una mujer sacó un paquete de la cartera y empezó a tirar migas de pan a las palomas. Pero las palomas todavía desconfiaban; se posaban histéricamente sobre los papeles y volvían a alzar vuelos insensatos sin tomar la comida. Me dieron ganas de emprenderla a patadas con las palomas, pero tuve lástima de la mujer; ¿cuántas veces habría hecho lo mismo con su chico o su chica desaparecidos?

»Crucé la calle y, al mirar para arriba, vi que las palomas se reorganizaban en una formación perfecta y volvían a posarse sobre el obelisco. En la esquina de la calle San Martín me esperaba mi amiga; su rostro delgado y pálido estaba en paz.

"Debió ver algo muy extraño en mi cara, porque se quedó mirándome, a punto de decir algo. Después movió la cabeza. "No lo tomes así, no lo tomes así', murmuró, y fue ella la que me pasó ahora la mano por los hombros. Pero yo hice una cosa horrible, horrible, de la que siempre me arrepentiré.

"Me zafé de un tirón y me puse a gritar en plena calle que cómo había que tomarlo, que cómo carajo había que tomarlo, y por qué no salían los hijos de puta que estaban escondidos detrás de las ventanas; pero aullando 
realmente como una loca energúmena, mientras ella enrojecía lo mismo que si la estuviera abofeteando.

»Protagonicé un verdadero escándalo. $\mathrm{Y}$ ¿te crees que salió alguien a ver qué pasaba, te crees que alguien se asomó? Ni un alma.

»-Lo siento - dijo Elena-, lo siento en el alma.

»Pero yo no lo sentía; era una cosa completamente distinta, horrible lo que me pasaba por dentro. Le dije a Elena que me regresaba a la plaza. Ella me miró un momento sin decir nada, y luego dio media vuelta y se volvió a su casa; seguramente la plaza estaba todavía vacía, o casi, no me acuerdo muy bien. Me senté en un banco a repetir: '¿cómo hay que tomarlo, carajo, cómo hay que tomarlo?', hasta que de tanto repetirla, la frase se fue suavizando.

"Miré hacia la Casa Rosada, dos granaderos montaban guardia. Entonces apoyé la nuca en el respaldo de hierro del banco y me puse a llorar, sin ruido, para que nadie se diera cuenta...

»Yo tampoco sé cómo hay que tomarlo. Pero hay que hacer de manera que se pueda respirar, ¿viste? Porque si no tomas aliento, vos también te morís. Y lo grave ni siquiera es que vos te mueras, sino que les regalás otro muerto.»

En 1979, Angel Rama llegó con Marta, su mujer, a la Universidad de Maryland. Primero fue profesor visitante y en 1981 lo nombraron titular del departamento de literatura latinoamericana. A Marta le habían invitado con anterioridad, en los cincuenta, en los sesenta, cuando prefirió Cuba a la Universidad de Yale y recibir el premio «Casa de las Américas». En 1979 empezó a dictar cursos y conferencias en catorce universidades, entre ellas Harvard y Princeton, hasta que el Departamento de Inmigración de Estados Unidos les negó la visa en 1983. De nuevo el exilio, de nuevo el salto en el vacío, como Marta lo había predicho en su entrevista con Igor Molina:

«Toda mi vida no ha sido más que una serie de saltos acrobáticos en el vacío. Mis increíbles peleas son siempre con el que puede pulverizarme. Mi enfrentamiento con el presidente Carlos Lleras, después de su arrasamiento de la Universidad, me valió lógicamente la expulsión de Colombia. Cuando se habían calmado las desastrosas consecuencias, acusé al ex presidente Alberto Lleras Camargo como agente norteamericano infiltrado en Visión. De la misma manera pasional me entregué de cuerpo y alma a la Revolución cubana, viéndola como el proyecto original y autónomo del 
socialismo que todos soñábamos. Cuando tuve la desgraciada certidumbre de que se alineaba en la órbita soviética me separé públicamente, con las consecuencias imaginables. Hoy estoy obsesionada con la pandilla salvaje que asesinó a Chile. Por las noches me despierto pensando en los tiranos, en Pinochet, en el asesino Banzer echando al río los cadáveres de los campesinos de Cochabamba, y me saltan las lágrimas como si el corazón fuera a rompérseme. Sigo siendo socialista, claro, pero del socialismo que todavía no llega al poder.»

En noviembre de 1982 coincidí con Marta en la Universidad de Smith. Tenía muchos deseos de divulgar su expulsión; hicimos una entrevista, la misma que se publicó en México en el periódico Novedades. Me dijo:

"Yo tenía ideas preconcebidas bastante estrechas sobre los Estados Unidos, nacidas, con razón, del profundo rechazo que nos producen las relaciones políticas entre los Estados Unidos y nuestros países. Aquí aprendí a apreciar las ventajas internas de la vida norteamericana, al menos para la mayoría de los ciudadanos de este país. Nuestros cinco hijos grandes (tres de Angel y dos míos), que son gente ya profesional, y compartían aquel unánime rechazo ante las nefastas intervenciones del Departamento de Estado en nuestra vida política y económica, vinieron a visitarnos y experimentaron el mismo cambio que nosotros. Fue como si ganáramos un país, cosa que en las actuales circunstancias nadie menosprecia. Al aceptar la permanencia en la Universidad de Maryland se abrió ante nosotros un período de estabilidad. Compramos un pequeño departamento en Washington, trasladamos allí nuestros cuatro mil libros de consulta y nuestra modesta colección de artistas latinoamericanos. Casa, biblioteca y un lugar óptimo para vivir un tiempo; los museos de Washington y la Library of Congress se parecieron bastante al paraíso.

"Nosotros amamos no a los Estados Unidos así como Estados Unidos, amamos sus buenas bibliotecas, sus buenas, buenísimas exposiciones de pintura y estamos encantados con los servicios sociales y cómo funciona la democracia para los norteamericanos. Es espléndida la atención a los enfermos, los handicapped, los inválidos, los niños, la atención profesional al ser humano.

"En el campo intelectual me he encontrado con que los alumnos a nivel universitario en las múltiples universidades visitadas leen los libros con una enorme devoción. Me he encontrado a colegas llenos de respeto por el trabajo intelectual. Cuando no hay sino un ejemplar de un libro le sacan fotocopias, lo hacen circular; en fin, he tenido demostraciones de respeto intelectual que nunca había visto a lo largo de mi vida. El interés por América Latina, su arte y su pintura es enorme. Viví contenta de descubrir una serie de cosas que pensaba que sólo bajo un verdadero 
socialismo - recuerda que soy anticomunista- podían darse, y aquí en los Estados Unidos vine a entender. Aquí ocurren, bajo el punto de vista social, y para mí han sido una gran experiencia.

»Un pensamiento liberal de izquierda — continuó Marta Traba- o un pensamiento socialista, como quieras llamarlo, está hoy día mal con todo el mundo; lo persiguen por igual la extrema derecha y la extrema izquierda. Pensar por cuenta propia es muy difícil hoy día. Para el sistema norteamericano es una especie de pecado capital; están demasiado acostumbrados al nivel de los desamparados recolectores de cosechas, a los ilegales.»

A la pregunta acerca de sus opiniones, Marta respondió:

"Voy a hacer un decálogo en pro y en contra; al menos de las sostenidas a lo largo de los años.

"Estoy a favor de:

- Puerto Rico libre.

- La Revolución cubana hasta 1971, cuando Castro definió completamente su alineación con Rusia.

- La Revolución nicaragüense, mientras sea hecha por el pueblo que fue capaz de derrocar una dictadura sangrienta y no se vuelva dependiente ni de Rusia ni de Cuba.

- El gobierno de Allende en Chile.

- La causa por los desaparecidos en la Argentina.

- La política de Carter por los Derechos Humanos.

- La liberación de presos políticos en Cuba.

- Juicio a los militares argentinos que nos hicieron perder Las Malvinas.

- La Junta Militar peruana inmediatamente después de derrocar a Belaúnde.

- Cualquier forma de gobierno socialista o progresista que signifique un cambio a fondo (slogan del actual gobierno de Colombia) en la distribución de riqueza, educación y servicios en nuestros países. $\gg$ Estoy totalmente en contra de:

- La invasión de EE. UU. a Santo Domingo en 1961 (para empezar sólo desde una fecha en que comencé a actuar públicamente).

- La invasión de Rusia a Checoslovaquia y a Afganistán.

- La dictadura militar argentina.

- La dictadura de otros países latinoamericanos: Uruguay, Paraguay, Chile.

- Los asesinatos perpetrados y protegidos por los gobiernos de El Salvador, Guatemala, Honduras.

- La intervención de los Estados Unidos (USA) en Centroamérica. 
- Las torturas dondequiera que se denuncien.

- Las falsas acusaciones de EE. UU. contra intelectuales latinoamericanos.

- El comunismo soviético como negación del socialismo.

"Es imposible resumir tantas luchas de solidaridad ... por el canal de Panamá, por los sindicatos polacos, ¿cómo acordarse de todas? ¿O de todas las firmas contra dictadores y torturadores?»

Después de volar a Colombia y permanecer en Bogotá tres meses, entre 1982 y 1983, Marta (quien hizo allá programas de televisión y fue nacionalizada colombiana - con honores- por su amigo el presidente Belisario Betancur) se instaló con Angel en la avenida de Notre Dame des Victoires, en París. A fines de diciembre de 1983 me escribió Magda Bogin:

"Me quedé días hundida en la depresión por la muerte de Marta y Angel Rama, como, me imagino, tú también. A Marta la vi en París en junio y julio, y me encantó más que nunca. Se había instalado en un enorme departamento junto al Palais Royal, y si pasaron una etapa difícil por la expulsión de Estados Unidos, para cuando llegué a París no se veía nada de vencimiento, sino todo lo contrario, pues me contaron con qué placer salían domingo tras domingo a unos centros Emmaus donde podían conseguir muebles antiguos por casi nada (me enseñaron su cama: 'sólo nos costó 70 francos'), y todo lo demás que habían comprado, puras gangas increíbles, ni una sola pieza que no fuera comprada en esas tiendas de la caridad católica en Francia. Y cuando le pregunté a Marta si volvería a Estados Unidos en caso de ganar el pleito con Washington, me dijo que no, que ya no se quería mudar... que se iba a ir d'içi au Père Lachaise, así en francés. De pura casualidad, nos encontramos en el mismo departamento del Talgo, regresando de Barcelona a París a finales de junio. Ella sabía que me había yo ido a España, pero no cuándo regresaba, y yo no sabía que ella tenía un departamento en una casa construida por Gaudí; así que fue de lo más sorprendente encontrarnos en el tren una encima de la otra (Marta pidió la cama de abajo).

"La última vez que la vi fue con Nina, que se quedó impresionadísima por la gran felicidad que Marta emanaba. Viéndola en su casa, en un ambiente que no era suyo, se sentía esa gran riqueza interior, por lo menos así me impresionó a mí también. Tenía Marta un gozo inmenso de la vida a través de una inteligencia poderosa y una enorme generosidad, una voluntad de incluir a todos - bueno, no sé si a todos, pero seguramente a muchos- en su modo de ser. Una gran apertura. 
»Aquí no hubo casi nada en los periódicos. Es como si nunca existieron Marta Traba y Angel Rama, como si no hubieran dado nada en los tres años que vivieron en este país (donde estuvieron más felices que nunca antes, me dijo Marta), pero hubo dos homenajes que, por lo menos, permitieron a sus amigos dar forma al dolor y romper el silencio. Jean Franco está desesperada; creo que adoraba a Rama como a un santo; que para ella era su ángel de la guardia.»

Hay seres que se dan; Rosario Castellanos fue una de las que se inmolan; Marta y ahora Julio Cortázar, que habría de morir tres meses más tarde. Todos teníamos nuestro Julio particular a quien le escribíamos, porque, milagrosamente, encontraba tiempo para contestar. Creo difícil que alguna mujer le haya escrito a Julio sin recibir respuesta. Como era bueno y tierno, había que comérselo, quitarle un pedazo, invitarlo, cuestionarlo, pedirle una opinión, «sólo unas cuantas líneas», solicitar un prólogo, una entrevista, una conversación telefónica, una firma o una fotografía. Rosario y Marta estuvieron siempre a la disposición de cuanto muchacho o muchacha tocaba a su puerta haciendo las consultas más peregrinas; dirigieron tesis, dieron conferencias, trabajaron hasta el agotamiento. ¿Cómo pudo Marta publicar 17 libros, 5 novelas y uno de cuentos? Vi a Marta alargar su curso de una hora a tres, su boca seca después del entusiasmo inicial. $Y$, sin embargo, allí seguía al pie del cañón. Dice José Emilio Pacheco "que el tiempo es la única verdadera posesión de una persona, un recurso no renovable, que disminuye vertiginosamente con cada segundo que pasa». Y se pregunta: "¿A qué horas escribirán, si la prensa, la radio, la televisión, la industria académica hacen sus más nobles, generosos y bien intencionados esfuerzos para que no puedan?» En Conversación al Sur, Marta afirma: «No soy yo la que flaquea, es mi maldito cuerpo.» A Marta nunca le vi una mueca de rechazo. La entrega de Alaíde Foppa también fue absoluta. Vidas de servicio, vidas de olvido de sí mismas. Vidas de absoluto amor. Incluso lo que le sucedía a su cuerpo, a su frágil envoltura humana, vino a ser secundario. Marta Traba relegó su cáncer. Tenía tanto trabajo que su deseo más grande era que éste no se lo impidiera. Y salió victorioso y se fue a vivir a Notre Dame des Victoires y así permaneció hasta el día en que, contenta -así la escuchó por teléfono Bell Chevigny unas horas antes de tomar el Avianca-, viajaría a Colombia al Encuentro de Escritores.

La novela inédita En algún lugar termina con un viaje en avión. Es una despedida. En el café, todo es ya una confusión de tazas, botellas y jarros de cerveza. Los amigos abrazan a Luis Vásquez, el protagonista de Marta. No saben si volverán a verse. Chao, chao, buen viaje, Luis siente 
que ya se va, que ya no está allí. Se acomoda la bolsa al hombro, el pasaje en el bolsillo, la tarjeta de abordar, pasa al mostrador de la compañía aérea y entra a un pasillo; un dolor raro en el pecho, algo puzante y frío adentro en las vísceras. Trata de aflojar la mandíbula, despacio todo, como recuperando la vida. El avión se mueve. Comienza un gran ruido atronador. Súbitamente ya no hay nada. Chao. Ni siquiera este viaje le ha impedido a Marta ejercer su generosidad. Como a Luis Vásquez, las manos nos sudan. Echamos la cabeza hacia atrás, cerramos los ojos y dejamos que corran y corran las lágrimas, hasta que el dolor pase y se adormezca. 
